TITLE:

\title{
ER stress response, peroxisome proliferation, mitochondrial unfolded protein response and Golgi stress response.
}

$\operatorname{AUTHOR}(S)$ :

Yoshida, Hiderou

\section{CITATION:}

Yoshida, Hiderou. ER stress response, peroxisome proliferation, mitochondrial unfolded protein response and Golgi stress response.. IUBMB life 2009, 61(9): 871-879

ISSUE DATE:

2009-09

URL:

http://hdl.handle.net/2433/87733

\section{RIGHT:}

(c) 2009 IUBMB.; This is not the published version. Please cite only the published version.; この論文は出版社版でありません。引用の際には 出版社版をご確認ご利用ください。 


\section{Critical Review}

ER Stress Response, Peroxisome Proliferation, Mitochondrial Unfolded Protein Response and Golgi Stress Response

Hiderou Yoshida

Department of Biophysics, Graduate School of Science, Kyoto University, Japan

\section{Correspondence}

H. Yoshida

Department of Biophysics, Graduate School of Science, Kyoto University,

Kitashirakawa-Oiwakecho, Sakyo-ku, Kyoto 606-8502, Japan

Tel: $+81+75-753-4201 . \quad$ Fax: $+81+75-753-3718$

E-mail: hide@biophysics.mbox.media.kyoto-u.ac.jp

Web site: http://www.eonet.ne.jp/ biophysics-kyoto/

Running Title: ORGANELLE AUTOREGULATION

Keywords mitochondrial retrograde signaling; ATF6; IRE1; XBP1;

unfolded protein response; PPAR; PEX 


\section{ABBREVIATIONS}

ER, endoplasmic reticulum; ERAD, ER-associated degradation; AARE, amino acid response element; ERSE, ER stress response element; UPRE, unfolded protein response element; PEX, peroxin; ORE, oleate response element; UPR, unfolded protein response; MURE, mitochondrial unfolded protein response element 


\section{Summary}

The endoplasmic reticulum (ER) response has been thought a

cytoprotective mechanism to cope with accumulation of unfolded proteins

in the ER. Recent progress has made a quantum leap revealing that ER

stress response can be regarded as an autoregulatory system adjusting

the ER capacity to cellular demand. This Copernican change raised a

novel fundamental question in cell biology: how do cells regulate the

capacity of each organelle in accordance with cellular needs? Though

this fundamental question has not been fully addressed yet, research about

each organelle has been advancing. The proliferation of the peroxisome

is regulated by the PPAR $\alpha$ pathway, whereas the abundance of

mitochondria appears to be regulated by mitochondrial retrograde signaling

and the mitochondrial unfolded protein response. The functional capacity

of the Golgi apparatus may be regulated by the mechanism of the Golgi

stress response. These observations strongly suggest the existence of

an elaborate network of organelle autoregulation in eukaryotic cells. 


\section{INTRODUCTION}

Eukaryotic cells contain a set of organelles that are specialized in specific cellular functions. The abundance of each organelle appears to be tightly and dynamically regulated in accordance with cellular demand. For instance, secretory cells such as plasma cells contain enormous amounts of the endoplasmic reticulum (ER), almost filling the cytoplasm, while exercise-conditioned skeletal muscle contains enlarged mitochondria [1]. Since most of the genes involved in organelle biogenesis reside in the nuclear genome, inter-organelle signaling between the nucleus and the organelle appears to regulate the autoregulation of the organelle abundance (Figure 1). It is highly possible that each organelle has sensor molecules that monitor whether the capacity is sufficient to satisfy various cellular demands. If the demand exceeds the capacity, an emergency signal is transmitted to the nucleus, and activates the transcription of relevant genes involved in the biogenesis of the organelle, leading to upregulation of the capacity and the abundance. However, the underlying 
mechanism of the organelles' autoregulation has not been fully clarified.

This short review will briefly summarize the recent progress of

research on the autoregulation of the abundance of organelles, including the ER, peroxisomes, mitochondria and Golgi apparatus.

\section{ER STRESS RESPONSE}

The ER is an organelle in which secretory and membrane proteins are synthesized, and proteins correctly folded by ER chaperones are transported to the Golgi apparatus [2]. Unfolded or misfolded proteins are retained in the ER and degraded by ER-associated degradation (ERAD) [3, 4]. If unfolded proteins build up in the ER, eukaryotic cells upregulate the expression of ER chaperones and components of ERAD machinery to enhance the capacity of folding and degradation of unfolded proteins, through the cytoprotective mechanism called the ER stress response or unfolded protein response [5-8].

Mammalian cells developed an elaborate mechanism of the ER 
stress response, which utilizes three sensor molecules monitoring the accumulation of unfolded proteins in the ER (ER stress) (Figure 2). PERK, a sensor-kinase localized in the ER membrane, phosphorylates the $\alpha$ subunit of eukaryotic initiation factor of translation (elF2 $\alpha$ ) in response to ER stress, leading to translational attenuation and then preventing further accumulation of unfolded proteins $[9,10]$. PERK also induces the expression of a transcription factor, ATF4, which binds to an enhancer element called AARE (amino acid response element) and is responsible for induction of antioxidative enzymes as well as proteins related to translation $[11,12]$.

ATF6 is a sensor-transcription factor embedded in the ER membrane [13]. Upon ER stress, ATF6 is transported to the Golgi apparatus and sequentially cleaved by proteases called S1P and S2P [14-16]. A cytoplasmic portion of ATF6 released from the Golgi apparatus translocates into the nucleus, binds to an enhancer element called ERSE (ER stress response element; the consensus sequence is 
CCAAT(N9)CCACG) and activates transcription of ER chaperone genes as

well as ERAD genes [17-20].

IRE1 is a sensor-RNase located in the ER membrane [21-24].

Upon sensing ER stress, IRE1 converts pre-mRNA of XBP1 into mature

mRNA by the mechanism of cytoplasmic mRNA splicing, leading to

translation of active transcription factor $\operatorname{pXBP} 1(\mathrm{~S})[25,26] . \quad \mathrm{pXBP} 1(\mathrm{~S})$

activates transcription of ER chaperone and ERAD genes as a homodimer

or a heterodimer with ATF6, whereas $\mathrm{pXBP1(U),} \mathrm{a} \mathrm{protein} \mathrm{translated} \mathrm{from}$

XBP1 pre-mRNA, enhances degradation of pXBP1(S) [17, 18, 27-30].

These response pathways operate not simultaneously but

sequentially [18]. In the early phase of the ER stress response, the PERK

pathway attenuates translation to facilitate folding of unfolded proteins,

without inducing expression of ER chaperones. If unfolded proteins still

persist, the ATF6 pathway increases the expression of ER chaperones to

enhance the folding of unfolded proteins. If the ATF6 pathway cannot

manage unfolded proteins, the expression of ERAD components is induced 
by the IRE1 pathway, leading to degradation of unfolded proteins. If these pathways cannot deal with the ER stress, compromised cells are disposed of by apoptotic cell death.

ER stress-induced apoptosis seems to be regulated by multiple pathways. The CHOP pathway has been analyzed extensively. CHOP is a transcription factor whose transcription is induced by ATF4 in response to ER stress, and which in turn activates the transcription of pro-apoptotic factor Bim [31]. ER stress-induced apoptosis is regulated by other pathways, including the IRE1-TRAF2-ASK1 pathway, the caspase-12 pathway and c-Abl [8].

The biological significance of ER stress response has been obscure since the physiological situations in which unfolded proteins accumulate in the ER were not known. ER stress can be artificially evoked either by treating cells with chemicals preventing protein folding such as tunicamycin and thapsigargin, or by expression of genetically mutated secretory proteins that cannot be folded correctly. However, 
organisms seldom ingest such substances, and it is not conceivable that the ER stress response has been developed to cope with genetic mutations of secretory proteins.

The answer came from the unexpected finding that XBP1, a key transcription factor essential for the ER stress response, is a regulator of the ER abundance in secretory cells, including plasma cells, pancreatic acinar cells and salivary gland cells [25, 26, 32, 33]. For instance, precursors of plasma cells (pre-B cells) have a trace amount of ER, whereas plasma cells secreting large amount of immunoglobulins have extensively developed ER to support production of immunoglobulin. Interestingly, XBP1 is indispensable for expansion of the ER, and the ER stress response is highly activated in plasma cells and other secretory cells, resulting in the induction of large amounts of ER chaperones as well as ERAD components. These observations suggest that the production of large amounts of immunoglobulin activates the ER stress response, leading to enhanced expression of ER chaperones and ERAD components 
as well as ER expansion. In other words, the ER stress response is a

mechanism to adjust the capacity of ER functions, including protein folding and ERAD, to cellular demand.

\section{PEROXISOME PROLIFERATION}

The peroxisome is an organelle where diverse biochemical reactions including $\beta$-oxidation of fatty acids and the detoxification of hydrogen peroxide occur [1]. The abundance of the peroxisome is dynamically regulated by the metabolic status in cells [34]. In budding yeast Saccharomyces cerevisiae, fatty acids such as oleate increase the peroxisomes [35], while methanol induces proliferation of this organelle in methylotrophic yeast Pichia pastoris [36], suggesting that cells tightly regulate the abundance of peroxisomes in accordance with cellular demand. In mammalian cells, the abundance of peroxisomes is enhanced by long chain fatty acids as well as hypolipidemic compounds such as clofibrate, phthalate esters used as plasticizers such as 
di(2-ethylhexyl) phthalate, and halogenated hydrocarbon solvents [34].

Though it is still controversial whether the peroxisome proliferates by fission or budding from the ER, many peroxisomal proteins, including peroxins (PEXs), contain a peroxisomal targeting signal instead of a signal sequence, and can be imported to the peroxisome post-translationally, independent of the ER function [37, 38].

The mechanism of peroxisome proliferation in response to fatty acids has been extensively studied in S. cerevisiae (Figure 3) [1, 35, 39-41]. Fatty acids bind and activate Zinc finger-type transcription factors Oaf1p and Pip2p/Oaf2p, which belong to the nuclear hormone receptor superfamily. A heterodimer of Oaf1p and Pip2p binds to an enhancer element called ORE (oleate response element: consensus sequence is $\mathrm{CGGN}_{15-18} \mathrm{CCG}$ ) and induces transcription of genes involved in peroxisome function, leading to peroxisome proliferation. The target genes of Oaf1-Pip2p include $\beta$-oxidation enzymes such as Pox1p (acyl CoA oxidase, which is a rate limiting enzyme of the $\beta$-oxidation pathway) and enzymes 
that degrade hydrogen peroxide, such as Cta1p (catalase A). Though

most of the peroxins that are involved in peroxisome biogenesis are not induced by fatty acids, peroxins such as Pex11p/Pmp27p and Pex25p, which are involved in peroxisome proliferation, are regulated by the OAF1-PIP2 pathway [42-54]. Interestingly, the promoter of PIP2 contains ORE, and its expression is induced by fatty acids, whereas the expression of Oaf1p is constitutive [54].

Budding yeast has another regulatory pathway for peroxisome proliferation called retrograde regulation (also called mitochondrial retrograde signaling: see below) (Figure 3) $[55,56]$. CIT2, which encodes the peroxisomal glyoxylate cycle enzyme citrate synthase 2, is transcriptionally activated in response to oleate. Transcriptional induction of CIT2 is regulated by three proteins: RTG1, RTG2 and RTG3. RTG1 and RTG3 encode basic helix-loop-helix transcription factors, while RTG2 is a cytoplasmic protein that shows no homology to known proteins (see the section about mitochondrial retrograde signaling). In the absence of 
oleate, RTG3 is hyperphosphorylated and RTG1 and RTG3 are localized in the cytoplasm. In response to oleate, RTG3 becomes partially dephosphorylated, and a heterodimer of RTG1 and RTG3 is transported to the nucleus and activates transcription of $\mathrm{CIT} 2$ by directly binding to an enhancer element called an R box (consensus sequence is GTCAC) in the CIT2 promoter. RTG2 is required for dephosphorylation and activation of RTG3, and may be involving in sensing of oleate. Though RTG genes are also required for transcriptional induction of POX1 and CTA1, regulation by RTGs appears to be indirect, since RTG1 and RTG3 do not bind to the ORE or the promoters of POX1 and CTA1 [57]. Interestingly, the RTG pathway is also activated by mitochondrial dysfunction such as $\rho^{0}$ petites blockade of the tricarboxylic acid cycle [58], indicating the crosstalk of autoregulatory systems between the peroxisome and the mitochondria.

The OAF1-PIP2 pathway is considerably conserved in mammalian cells $[39,59]$. When long chain fatty acids bind to the ligand binding domain of PPAR $\alpha$ (mammalian Zinc finger type transcription factor 
belonging to the nuclear hormone receptor superfamily), PPAR $\alpha$ becomes activated, forms a heterodimer with a nuclear hormone receptor, $\mathrm{RXR}$, and binds to an enhancer element called PPRE (peroxisome proliferator-response element: the consensus sequence is AGGTCA(N)AGGTCA). PPAR $\alpha$ induces expression of peroxisomal proteins including lipid metabolizing enzymes as well as PEX11 $\alpha$ [60], leading to proliferation of the peroxisome $[61,62]$. Chemicals that induce peroxisome proliferation such as clofibrate (peroxisome proliferators) are thought to directly bind and activate PPAR $\alpha$.

When the number of the peroxisome is excessive as compared for cellular demand, the abundance of the organelle is reduced by the mechanism of selective degradation called pexophagy. Pexophagy utilizes a non-selective autophagy system as well as pexophagy-specific pathways to form pexophagosomes engulfing the organelles and to degrade them in lysosomes. The mechanism of pexophagy has been well analyzed in methylotrophic yeasts Hansenula polymorpha and P. pastoris 
[36]. In P. pastoris, two modes of pexophagy, macropexophagy and micropexophagy, have been reported. Macropexophagy is restricted to mature peroxisomes, leaving immature peroxisomal vesicles intact. This selectivity relies on two proteins involved in peroxisome biogenesis. Pex3p, a peroxin that is absent from the mature peroxisome and degraded by the proteasome, prevents pexophagy of the immature peroxisome, whereas Pex14p, a potential docking protein for initial factors of pexophagy such as Atg11p, facilitates pexophagy of the mature peroxisome.

Autophagy specific to the mitochondria (mitophagy) and ER (ER-phagy) has been reported. Mitophagy is induced by nutrient deprivation in mammalian cells [63], while it is also involved in elimination of aged and dysfunctional mitochondria since mitochondria are prone to reactive oxygen species [64]. Nutrient starvation triggers the delivery of the ER to the vacuole via autophagy [65]. In addition, ER stress increases the expression of ATG8, a cruicial component required for autophagosome formation, and induces ER-phagy in yeast [66-68]. Deletion of ATG8 
prevents ER-containing autophagosomes and impairs the ability of the cells to survive ER stress. In mammalian cells, autophagy is activated in response to ER stress, and protects cells from ER stress [69-72]. These organelle-specific type of autophagy may be responsible for downregulation of excessive amounts of these organelles, as well as disposal of malfunctioning organelles.

\section{MITOCHONDRIAL RETROGRADE SIGNALING}

The mitochondria is an organelle producing ATP from acetyl CoA in the TCA cycle and the respiratory chain [73]. It has been reported that the mass of mammalian mitochondria is increased in cells that have defects in the respiratory chain [74], in adipose tissue upon cold shock [75], or exercise-conditioned skeletal muscle [1], suggesting that the mitochondria has an autoregulatory system to adjust its function for cellular demand, in order to keep ATP levels constant [76]. Though transcription factors and co-activators such as Tfam, NRF1, NRF2, SP1, YY1, CREB, 
MEF2 and PGC-1 alpha are reported to be involved in the transcriptional induction of genes responsible for mitochondrial function and biogenesis, the mitochondrial biosynthetic program appears to be regulated by multiple transcriptional regulatory pathways, including the mitochondrial retrograde signaling and mitochondrial unfolded protein response.

When the function of the mitochondria is compromised and the cellular ATP levels drop, eukaryotic cells activate the mitochondrial retrograde signaling and upregulate the transcription of nuclear genes involved in mitochondrial function to restore the ATP levels $[56,77]$. Mitochondrial retrograde signaling is observed in yeast as well as in mammals, though the underlying mechanism appears not to be highly conserved [78].

RTG3 and RTG1 are key transcription factors regulating mitochondrial retrograde signaling in budding yeast (Figure 3$)[55,58$, 79-86]. In normal conditions, RTG3 is hyperphosphorylated and localized in the cytoplasm. A cytoplasmic protein, Mks1p, is a negative regulator of 
RTG3 that enhances RTG3 phosphorylation. RTG2 is a cytoplasmic protein that contains an ATP-binding domain and thought to monitor cellular ATP levels. Upon a decrease of mitochondrial respiratory capacity, RTG2 promotes dephosphorylation of RTG3, leading to translocation of an RTG3-RTG1 heterodimer to the nucleus. Grr1p, another positive regulator, contains an F-box motif and mediates ubiqutination and degradation of Mks1p. Ubiquitination of Mks1p by Grr1p is blocked by negative regulators, such as 14-3-3 proteins called Bmh1p and Bmh2p. RTG3-RTG1 binds to an enhancer element called the R box (consensus sequence is GTCAC) and activates transcription of CIT2, DLD3, CIT1, ACO1, IDH1 and IDH2. CIT2 encodes a peroxisomal citrate synthase that helps produce citrate from carbon source such as fatty acids, acetate and ethanol via the glyoxylate cycle (Figure 3). DLD3 encodes a cytoplasmic D-lactate dehydrogenase, and may be involved in regeneration of $\mathrm{NAD}^{+}$ due to the buildup of NADH in respiration-deficient cells. CIT1, ACO1, IDH1and IDH2 encode enzymes involved in the first three steps of the TCA 
cycle.

Mitochondrial retrograde signaling (also referred to as

mitochondrial stress signaling) has been less studied in mammalian cells [78]. Mitochondrial dysfunction caused by partial depletion of mitochondrial DNA or treatment with mitochondria-specific inhibitors such as CCCP induces stress signaling that is associated with increased cytoplasmic free $\mathrm{Ca}^{2+}$ and upregulation of a number of genes involved in $\mathrm{Ca}^{2+}$ transport and storage, including Ryanodine receptor, calreticulin and calsequestrin, though the link to mitochondrial autoregulation remains obscure.

\section{MITOCHONDRIAL UNFOLDED PROTEIN RESPONSE}

Mitochondria have an autoregulatory system similar to the ER stress response (Figure 4) $[73,87]$. Accumulation of unfolded proteins in the mitochondria induces the mitochondrial unfolded protein response $\left(\mathrm{UPR}^{\mathrm{mt}}\right)$, leading to enhanced expression of mitochondrial chaperones 
including HSP70 and HSP60 in Caenorhabditis elegans (hsp-6 and hsp-60, respectively) [87]. Four essential components of UPR ${ }^{\mathrm{mt}}$ have been identified in C. elegans: CLPP-1 is a mitochondrial matrix protease that is similar to bacterial protease ClpP. Though bacterial ClpP is associated with AAA-ATPases such as ClpA and ClpX, C. elegans has no obvious ClpA homolog and two homologs of ClpX, though knock down of the two ClpX homologs did not affect UPR ${ }^{\mathrm{mt}}$. The second component is a transcription factor, DVE-1. DVE-1 contains a homeobox, and translocates into the nucleus upon UPR ${ }^{\mathrm{mt}}$. ChIP assays revealed that DVE-1 binds the promoters of hsp- 6 and hsp- 60 . The third component is a ubiquitin-like protein, UBL5. UBL5 binds to DVE-1, and its expression is induced in response to UPR ${ }^{\mathrm{mt}}$. The fourth component is RheB. Rhe1 is a GTPase implicated in signaling via TOR. The current working hypothesis of UPR ${ }^{\mathrm{mt}}$ in C. elegans is as follows [87]: unfolded proteins are refolded by mitochondrial chaperones and degraded by mitochondrial proteases such as SPG7. If unfolded proteins overwhelm mitochondrial 
chaperones, they are processed by CLPP-1 and the resultant peptides are transported to the cytosol via a mitochondrial inner membrane protein, MDL-1. The peptides released to the cytosol activate DVE-1 and UBL5, and enhance their association. Then DVE-1 enters the nucleus and activates the transcription of mitochondrial chaperone genes. RheB and TOR may be involved in the negative feedback loop of UPR ${ }^{\mathrm{mt}}$. In mammals, UPR ${ }^{\mathrm{mt}}$ induces the expression of mitochondrial chaperones and proteases, including HSP60, HSP10, mtDnaJ and CIpP $[73,88-91]$. Promoters of these UPR ${ }^{\mathrm{mt}}$ target genes contain a binding site for transcription factors CHOP and C/EBP $\beta$, flanked by a pair of conserved cis-elements called mitochondrial UPR elements (MUREs). Transcription of $\mathrm{CHOP}$ and C/EBP $\beta$ is induced by UPR ${ }^{\mathrm{mt}}$, possibly by binding of cJUN activated by JNK2 to an AP-1 site of the CHOP promoter. It remains to be clarified whether the UPR ${ }^{\mathrm{mt}}$ pathway in C. elegans is conserved in mammals, and whether UPR ${ }^{\mathrm{mt}}$ actually regulates the capacity of mitochondria in accordance with cellular demand. 


\section{GOLGI STRESS RESPONSE}

If the ER stress response enhances the capacity of ER function,

large amounts of secretory proteins are transported to the Golgi apparatus,

probably causing insufficiency of Golgi function (Golgi stress). It is

possible that the mechanism of autoregulation called the Golgi stress

response evolved to cope with such a stressful situation. Interestingly the

Golgi apparatus is well developed in secretory cells such as a secretory

mucous cells of the intestinal Brunner's glands, which require a high level

of Golgi function. Brunner's gland cells synthesize a large amount of

mucin that contains enormous amounts of O-linked sugar chains. Since

O-linked sugar chains are conjugated to secretory proteins in the Golgi

apparatus, the demand for Golgi function is thought to be very high in

Brunner's cells. Moreover, the Golgi apparatus of prolactin cells and

mammary gland cells of female mice is known to develop dynamically in

response to increased production of prolactin and milk proteins induced by 
the sucking stimulus. These observations strongly suggest the existence

of the Golgi stress response to adjust the capacity of the Golgi apparatus to cellular demand in eukaryotic cells. Actually, the expression of genes involved in Golgi function was increased when mammalian as well as yeast cells were treated with monensin or nigericin, chemicals that impair Golgi function. Identification of enhancer elements, transcription factors and sensors responsible for transcriptional induction would reveal the molecular mechanism of the Golgi stress response pathway.

\section{CONCLUDING REMARKS}

Though the human body consists of various types of cells such as neurons, muscle cells and lymphocytes, the basic structures of these cells are very similar, and are comprised of organelles including the nucleus, ER, mitochondria, peroxisomes, Golgi apparatus, lysosomes and endosomes. Thus, the capacity of each organelle has to be highly adaptive, in order to support various types of functions in a variety of cells. In other words, the 
autoregulation of organelle capacity is a fundamental process for

multicellular organisms. Achieving a complete view of the network of

organelle autoregulation should be indispensable for understanding the sophisticated homeostatic mechanisms of eukaryotic cells, as well as the diseases related to loss of organellar function [8, 92-94].

\section{ACKNOWLEDGEMENTS}

We thank Dr. Elizabeth Nakajima for critical reading of the manuscript, and Ms. Kaoru Miyagawa for technical-secretarial assistance. This work was supported by the Yamada Science Foundation, the PRESTO-SORST program of the Japan Science and Technology Agency, and grants from the Ministry of Education, Culture, Sports, Science, and Technology (MEXT) of Japan (No. 19370086, and 20052014). It was also financially supported in part by the Global Center of Excellence Program A06 "Formation of a Strategic Base for Biodiversity and Evolutionary Research: from Genome to Ecosystem” of MEXT. 


\section{REFERENCES}

1. Hood, D. A.Irrcher, I.Ljubicic, V.andJoseph, A. M. (2006)

Coordination of metabolic plasticity in skeletal muscle. $J$ Exp Biol 209, 2265-2275.

2. Gething, M.-J. (1997) Guidebook to Molecular Chaperones and Protein-Folding Catalysts. Oxford University Press, Oxford.

3. Brodsky, J. L. (2007) The protective and destructive roles played by molecular chaperones during ERAD (endoplasmic-reticulum-associated degradation). Biochem J 404, 353-363.

4. Ruddock, L. W.andMolinari, M. (2006) N-glycan processing in ER quality control. J Cell Sci 119, 4373-4380.

5. Malhotra, J. D.andKaufman, R. J. (2007) The endoplasmic reticulum and the unfolded protein response. Semin Cell Dev Biol 18, 716-731.

6. Mori, K. (2000) Tripartite management of unfolded proteins in the endoplasmic reticulum. Cell 101, 451-454.

7. Ron, D.andWalter, P. (2007) Signal integration in the endoplasmic reticulum unfolded protein response. Nat Rev Mol Cell Biol 8, 519-529.

8. Yoshida, H. (2007) ER stress and diseases. FEBS J 274, 630-658.

9. Harding, H. P.Zhang, Y.Bertolotti, A.Zeng, H.andRon, D. (2000) Perk is essential for translational regulation and cell survival during the unfolded protein response. Mol Cell 5, 897-904.

10. Harding, H. P.Zhang, Y.andRon, D. (1999) Protein translation and folding are coupled by an endoplasmic-reticulum- resident kinase. Nature 397, 271-274.

11. Harding, H. P.Novoa, I.Zhang, Y.Zeng, H.Wek, R.Schapira, M.andRon, D. (2000) Regulated translation initiation controls stress-induced gene expression in mammalian cells. Mol Cell 6, 
1099-1108.

12. Harding, H. P.Zhang, Y.Zeng, H.Novoa, I.Lu, P. D.Calfon, M.Sadri, N.Yun, C.Popko, B.Paules, R.Stojdl, D. F.Bell, J. C.Hettmann, T.Leiden, J. M.andRon, D. (2003) An integrated stress response regulates amino acid metabolism and resistance to oxidative stress. Mol Cell 11, 619-633.

13. Yoshida, H.Haze, K.Yanagi, H.Yura, T.andMori, K. (1998) Identification of the cis-acting endoplasmic reticulum stress response element responsible for transcriptional induction of mammalian glucose-regulated proteins. Involvement of basic leucine zipper transcription factors. J Biol Chem 273, 33741-33749.

14. Haze, K.Okada, T.Yoshida, H.Yanagi, H.Yura, T.Negishi, M.andMori, K. (2001) Identification of the G13 (cAMP-response-element-binding protein-related protein) gene product related to activating transcription factor 6 as a transcriptional activator of the mammalian unfolded protein response. Biochem J 355, 19-28.

15. Haze, K.Yoshida, H.Yanagi, H.Yura, T.andMori, K. (1999) Mammalian transcription factor ATF6 is synthesized as a transmembrane protein and activated by proteolysis in response to endoplasmic reticulum stress. Mol Biol Cell 10, 3787-3399.

16. Ye, J.Rawson, R. B.Komuro, R.Chen, X.Dave, U. P.Prywes, R.Brown, M. S.andGoldstein, J. L. (2000) ER stress induces cleavage of membrane-bound ATF6 by the same proteases that process SREBPs. Mol Cell 6, 1355-1364.

17. Yamamoto, K.Sato, T.Matsui, T.Sato, M.Okada, T.Yoshida, H.Harada, A.andMori, K. (2007) Transcriptional induction of mammalian ER quality control proteins is mediated by single or combined action of ATF6alpha and XBP1. Dev Cell 13, 365-376.

18. Yoshida, H.Matsui, T.Hosokawa, N.Kaufman, R. J.Nagata, K.andMori, K. (2003) A time-dependent phase shift in the mammalian unfolded protein response. Dev Cell 4, 265-271. 
19. Yoshida, H.Okada, T.Haze, K.Yanagi, H.Yura, T.Negishi, M.andMori, K. (2000) ATF6 activated by proteolysis binds in the presence of NF-Y (CBF) directly to the cis-acting element responsible for the mammalian unfolded protein response. $M o l$ Cell Biol 20, 6755-6767.

20. Yoshida, H.Okada, T.Haze, K.Yanagi, H.Yura, T.Negishi, M.andMori, K. (2001) Endoplasmic reticulum stress-induced formation of transcription factor complex ERSF including NF-Y $(\mathrm{CBF})$ and activating transcription factors 6alpha and 6beta that activates the mammalian unfolded protein response. Mol Cell Biol 21, 1239-1248.

21. Iwawaki, T.Hosoda, A.Okuda, T.Kamigori, Y.Nomura-Furuwatari, C.Kimata, Y.Tsuru, A.andKohno, K. (2001) Translational control by the ER transmembrane kinase/ribonuclease IRE1 under ER stress. Nat Cell Biol 3, 158-164.

22. Tirasophon, W.Lee, K.Callaghan, B.Welihinda, A.andKaufman, R. J. (2000) The endoribonuclease activity of mammalian IRE1 autoregulates its mRNA and is required for the unfolded protein response. Genes Dev 14, 2725-2736.

23. Tirasophon, W.Welihinda, A. A.andKaufman, R. J. (1998) A stress response pathway from the endoplasmic reticulum to the nucleus requires a novel bifunctional protein kinase/endoribonuclease (Ire1p) in mammalian cells. Genes Dev 12, 1812-1824.

24. Urano, F.Wang, X.Bertolotti, A.Zhang, Y.Chung, P.Harding, H. P.andRon, D. (2000) Coupling of stress in the ER to activation of JNK protein kinases by transmembrane protein kinase IRE1. Science 287, 664-666.

25. Calfon, M.Zeng, H.Urano, F.Till, J. H.Hubbard, S. R.Harding, H. P.Clark, S. G.andRon, D. (2002) IRE1 couples endoplasmic reticulum load to secretory capacity by processing the XBP-1 mRNA. Nature 415, 92-96.

26. Yoshida, H.Matsui, T.Yamamoto, A.Okada, T.andMori, K. (2001) $\mathrm{XBP} 1 \mathrm{mRNA}$ is induced by ATF6 and spliced by IRE1 in response 
to ER stress to produce a highly active transcription factor. Cell 107, 881-891.

27. Adachi, Y.Yamamoto, K.Okada, K.Yoshida, H.Harada, A.andMori, K. (2008) ATF6 is a transcription factor specialized in the regulation of quality control proteins in the endoplasmic reticulum. Cell Struct Funct 33, 75-89.

28. Yoshida, H. (2007) Unconventional splicing of XBP-1 mRNA in the unfolded protein response. Antioxid Redox Signal 9, 2323-2333.

29. Yoshida, H.Nadanaka, S.Sato, R.andMori, K. (2006) XBP1 is Critical to Protect Cells from Endoplasmic Reticulum Stress: Evidence from Site-2 Protease-deficient Chinese Hamster Ovary Cells. Cell Struct Funct 31, 109-116.

30. Yoshida, H.Oku, M.Suzuki, M.andMori, K. (2006) pXBP1(U) encoded in XBP1 pre-mRNA negatively regulates unfolded protein response activator pXBP1(S) in mammalian $\mathrm{ER}$ stress response. $J$ Cell Biol 172, 565-575.

31. Puthalakath, H.O'Reilly, L. A.Gunn, P.Lee, L.Kelly, P. N.Huntington, N. D.Hughes, P. D.Michalak, E. M.McKimm-Breschkin, J.Motoyama, N.Gotoh, T.Akira, S.Bouillet, P.andStrasser, A. (2007) ER stress triggers apoptosis by activating BH3-only protein Bim. Cell 129, 1337-1349.

32. Lee, A. H.Chu, G. C.Iwakoshi, N. N.andGlimcher, L. H. (2005) $\mathrm{XBP}-1$ is required for biogenesis of cellular secretory machinery of exocrine glands. Embo J 24, 4368-4380.

33. Reimold, A. M.Iwakoshi, N. N.Manis, J.Vallabhajosyula, P.Szomolanyi-Tsuda, E.Gravallese, E. M.Friend, D.Grusby, M. J.Alt, F.andGlimcher, L. H. (2001) Plasma cell differentiation requires the transcription factor XBP-1. Nature 412, 300-307.

34. Lock, E. A.Mitchell, A. M.andElcombe, C. R. (1989) Biochemical mechanisms of induction of hepatic peroxisome proliferation. Annu Rev Pharmacol Toxicol 29, 145-163.

35. Veenhuis, M.Mateblowski, M.Kunau, W. H.andHarder, W. (1987) Proliferation of microbodies in Saccharomyces cerevisiae. Yeast 3, 
77-84.

36. Sakai, Y.Oku, M.van der Klei, I. J.andKiel, J. A. (2006) Pexophagy: autophagic degradation of peroxisomes. Biochim Biophys Acta 1763, 1767-1775.

37. Fujiki, Y. (2000) Peroxisome biogenesis and peroxisome biogenesis disorders. FEBS Lett 476, 42-46.

38. Fujiki, Y.Miyata, N.Matsumoto, N.andTamura, S. (2008) Dynamic and functional assembly of the AAA peroxins, Pex1p and Pex6p, and their membrane receptor Pex26p involved in shuttling of the PTS1 receptor Pex5p in peroxisome biogenesis. Biochem Soc Trans 36, 109-113.

39. Platta, H. W.andErdmann, R. (2007) Peroxisomal dynamics. Trends Cell Biol 17, 474-484.

40. Karpichev, I. V.andSmall, G. M. (2000) Evidence for a novel pathway for the targeting of a Saccharomyces cerevisiae peroxisomal protein belonging to the isomerase/hydratase family. J Cell Sci 113 ( Pt 3), 533-544.

41. Karpichev, I. V.Luo, Y.Marians, R. C.andSmall, G. M. (1997) A complex containing two transcription factors regulates peroxisome proliferation and the coordinate induction of beta-oxidation enzymes in Saccharomyces cerevisiae. Mol Cell Biol 17, 69-80.

42. Rottensteiner, H.Wabnegger, L.Erdmann, R.Hamilton, B.Ruis, H.Hartig, A.andGurvitz, A. (2003) Saccharomyces cerevisiae PIP2 mediating oleic acid induction and peroxisome proliferation is regulated by Adr1p and Pip2p-Oaf1p. J Biol Chem 278, 27605-27611.

43. Rottensteiner, H.Palmieri, L.Hartig, A.Hamilton, B.Ruis, H.Erdmann, R.andGurvitz, A. (2002) The peroxisomal transporter gene ANT1 is regulated by a deviant oleate response element (ORE): characterization of the signal for fatty acid induction. Biochem J 365, 109-117.

44. Gurvitz, A.Hamilton, B.Hartig, A.Ruis, H.Dawes, I. W.andRottensteiner, H. (1999) A novel element in the promoter of 
the Saccharomyces cerevisiae gene SPS19 enhances

ORE-dependent up-regulation in oleic acid and is essential for de-repression. Mol Gen Genet 262, 481-492.

45. Gurvitz, A.Rottensteiner, H.Hiltunen, J. K.Binder, M.Dawes, I. W.Ruis, H.andHamilton, B. (1997) Regulation of the yeast SPS19 gene encoding peroxisomal 2,4-dienoyl-CoA reductase by the transcription factors Pip2p and Oaf1p: beta-oxidation is dispensable for Saccharomyces cerevisiae sporulation in acetate medium. Mol Microbiol 26, 675-685.

46. Smith, J. J.Sydorskyy, Y.Marelli, M.Hwang, D.Bolouri, H.Rachubinski, R. A.andAitchison, J. D. (2006) Expression and functional profiling reveal distinct gene classes involved in fatty acid metabolism. Mol Syst Biol 2, 20060009.

47. Tam, Y. Y.Torres-Guzman, J. C.Vizeacoumar, F. J.Smith, J. J.Marelli, M.Aitchison, J. D.andRachubinski, R. A. (2003) Pex11-related proteins in peroxisome dynamics: a role for the novel peroxin Pex27p in controlling peroxisome size and number in Saccharomyces cerevisiae. Mol Biol Cell 14, 4089-4102.

48. Smith, J. J.Marelli, M.Christmas, R. H.Vizeacoumar, F. J.Dilworth, D. J.Ideker, T.Galitski, T.Dimitrov, K.Rachubinski, R. A.andAitchison, J. D. (2002) Transcriptome profiling to identify genes involved in peroxisome assembly and function. $J$ Cell Biol 158, 259-271.

49. Marshall, P. A.Dyer, J. M.Quick, M. E.andGoodman, J. M. (1996) Redox-sensitive homodimerization of Pex11p: a proposed mechanism to regulate peroxisomal division. J Cell Biol 135, 123-137.

50. Sakai, Y.Marshall, P. A.Saiganji, A.Takabe, K.Saiki, H.Kato, N.andGoodman, J. M. (1995) The Candida boidinii peroxisomal membrane protein Pmp30 has a role in peroxisomal proliferation and is functionally homologous to Pmp27 from Saccharomyces cerevisiae. J Bacteriol 177, 6773-6781.

51. Marshall, P. A.Krimkevich, Y. I.Lark, R. H.Dyer, J. M.Veenhuis, 
M.andGoodman, J. M. (1995) Pmp27 promotes peroxisomal proliferation. J Cell Biol 129, 345-355.

52. Fagarasanu, A.Fagarasanu, M.andRachubinski, R. A. (2007) Maintaining peroxisome populations: a story of division and inheritance. Annu Rev Cell Dev Biol 23, 321-344.

53. Vizeacoumar, F. J.Torres-Guzman, J. C.Tam, Y. Y.Aitchison, J. D.andRachubinski, R. A. (2003) YHR150w and YDR479c encode peroxisomal integral membrane proteins involved in the regulation of peroxisome number, size, and distribution in Saccharomyces cerevisiae. J Cell Biol 161, 321-332.

54. Rottensteiner, H.Kal, A. J.Hamilton, B.Ruis, H.andTabak, H. F. (1997) A heterodimer of the Zn2Cys6 transcription factors Pip2p and Oaf1p controls induction of genes encoding peroxisomal proteins in Saccharomyces cerevisiae. Eur J Biochem 247, 776-783.

55. Chelstowska, A.andButow, R. A. (1995) RTG genes in yeast that function in communication between mitochondria and the nucleus are also required for expression of genes encoding peroxisomal proteins. J Biol Chem 270, 18141-18146.

56. Liu, Z.andButow, R. A. (2006) Mitochondrial retrograde signaling. Annu Rev Genet 40, 159-185.

57. Kos, W.Kal, A. J.van Wilpe, S.andTabak, H. F. (1995) Expression of genes encoding peroxisomal proteins in Saccharomyces cerevisiae is regulated by different circuits of transcriptional control. Biochim Biophys Acta 1264, 79-86.

58. Liao, X. S.Small, W. C.Srere, P. A.andButow, R. A. (1991) Intramitochondrial functions regulate nonmitochondrial citrate synthase (CIT2) expression in Saccharomyces cerevisiae. Mol Cell Biol 11, 38-46.

59. Phelps, C.Gburcik, V.Suslova, E.Dudek, P.Forafonov, F.Bot, N.MacLean, M.Fagan, R. J.andPicard, D. (2006) Fungi and animals may share a common ancestor to nuclear receptors. Proc Natl Acad Sci U SA 103, 7077-7081. 
60. Schrader, M.Reuber, B. E.Morrell, J. C.Jimenez-Sanchez, G.Obie, C.Stroh, T. A.Valle, D.Schroer, T. A.andGould, S. J. (1998)

Expression of PEX11beta mediates peroxisome proliferation in the absence of extracellular stimuli. J Biol Chem 273, 29607-29614.

61. Shimizu, M.Yamashita, D.Yamaguchi, T.Hirose, F.andOsumi, T. (2006) Aspects of the regulatory mechanisms of PPAR functions: analysis of a bidirectional response element and regulation by sumoylation. Mol Cell Biochem 286, 33-42.

62. Shimizu, M.Takeshita, A.Tsukamoto, T.Gonzalez, F. J.andOsumi, T. (2004) Tissue-selective, bidirectional regulation of PEX11 alpha and perilipin genes through a common peroxisome proliferator response element. Mol Cell Biol 24, 1313-1323.

63. Elmore, S. P.Qian, T.Grissom, S. F.andLemasters, J. J. (2001) The mitochondrial permeability transition initiates autophagy in rat hepatocytes. FASEB J15, 2286-2287.

64. Kim, I.Rodriguez-Enriquez, S.andLemasters, J. J. (2007) Selective degradation of mitochondria by mitophagy. Arch Biochem Biophys 462, 245-253.

65. Hamasaki, M.Noda, T.Baba, M.andOhsumi, Y. (2005) Starvation triggers the delivery of the endoplasmic reticulum to the vacuole via autophagy in yeast. Traffic 6, 56-65.

66. Bernales, S.Schuck, S.andWalter, P. (2007) ER-phagy: selective autophagy of the endoplasmic reticulum. Autophagy 3, 285-287.

67. Kruse, K. B.Brodsky, J. L.andMcCracken, A. A. (2006) Autophagy: an ER protein quality control process. Autophagy 2, 135-137.

68. Yorimitsu, T.Nair, U.Yang, Z.andKlionsky, D. J. (2006)

Endoplasmic reticulum stress triggers autophagy. J Biol Chem 281, 30299-30304.

69. Kamimoto, T.Shoji, S.Hidvegi, T.Mizushima, N.Umebayashi, K.Perlmutter, D. H.andYoshimori, T. (2006) Intracellular inclusions containing mutant alpha1-antitrypsin $\mathrm{Z}$ are propagated in the absence of autophagic activity. $J$ Biol Chem 281, 4467-4476.

70. Kouroku, Y.Fujita, E.Tanida, I.Ueno, T.Isoai, A.Kumagai, 
H.Ogawa, S.Kaufman, R. J.Kominami, E.andMomoi, T. (2007) ER stress (PERK/eIF2alpha phosphorylation) mediates the polyglutamine-induced LC3 conversion, an essential step for autophagy formation. Cell Death Differ 14, 230-239.

71. Ogata, M.Hino, S.Saito, A.Morikawa, K.Kondo, S.Kanemoto, S.Murakami, T.Taniguchi, M.Tanii, I.Yoshinaga, K.Shiosaka, S.Hammarback, J. A.Urano, F.andImaizumi, K. (2006) Autophagy is activated for cell survival after endoplasmic reticulum stress. Mol Cell Biol 26, 9220-9231.

72. Ding, W. X.Ni, H. M.Gao, W.Hou, Y. F.Melan, M. A.Chen, X.Stolz, D. B.Shao, Z. M.andYin, X. M. (2007) Differential effects of endoplasmic reticulum stress-induced autophagy on cell survival. J Biol Chem 282, 4702-4710.

73. Ryan, M. T.andHoogenraad, N. J. (2007) Mitochondrial-nuclear communications. Annu Rev Biochem 76, 701-722.

74. Wallace, D. C. (2005) A mitochondrial paradigm of metabolic and degenerative diseases, aging, and cancer: a dawn for evolutionary medicine. Annu Rev Genet 39, 359-407.

75. Scarpulla, R. C. (2002) Transcriptional activators and coactivators in the nuclear control of mitochondrial function in mammalian cells. Gene 286, 81-89.

76. Leary, S. C.andShoubridge, E. A. (2003) Mitochondrial biogenesis: which part of "NO" do we understand? Bioessays 25, 538-541.

77. Butow, R. A.andAvadhani, N. G. (2004) Mitochondrial signaling: the retrograde response. $\mathrm{Mol}$ Cell 14, 1-15.

78. Amuthan, G.Biswas, G.Zhang, S. Y.Klein-Szanto, A.Vijayasarathy, C.andAvadhani, N. G. (2001) Mitochondria-to-nucleus stress signaling induces phenotypic changes, tumor progression and cell invasion. Embo J 20, 1910-1920.

79. Giannattasio, S.Liu, Z.Thornton, J.andButow, R. A. (2005) Retrograde response to mitochondrial dysfunction is separable from TOR1/2 regulation of retrograde gene expression. $J$ Biol Chem 280, 42528-42535. 
80. Liu, Z.Spirek, M.Thornton, J.andButow, R. A. (2005) A novel degron-mediated degradation of the RTG pathway regulator, Mks1p, by SCFGrr1. Mol Biol Cell 16, 4893-4904.

81. Ferreira Junior, J. R.Spirek, M.Liu, Z.andButow, R. A. (2005) Interaction between $\operatorname{Rtg} 2 \mathrm{p}$ and $\mathrm{Mks} 1 \mathrm{p}$ in the regulation of the RTG pathway of Saccharomyces cerevisiae. Gene 354, 2-8.

82. Liu, Z.Sekito, T.Spirek, M.Thornton, J.andButow, R. A. (2003) Retrograde signaling is regulated by the dynamic interaction between Rtg2p and Mks1p. Mol Cell 12, 401-411.

83. Sekito, T.Thornton, J.andButow, R. A. (2000)

Mitochondria-to-nuclear signaling is regulated by the subcellular localization of the transcription factors Rtg1p and Rtg3p. Mol Biol Cell 11, 2103-2115.

84. Liu, Z.andButow, R. A. (1999) A transcriptional switch in the expression of yeast tricarboxylic acid cycle genes in response to a reduction or loss of respiratory function. Mol Cell Biol 19, 6720-6728.

85. Rothermel, B. A.Thornton, J. L.andButow, R. A. (1997) Rtg3p, a basic helix-loop-helix/leucine zipper protein that functions in mitochondrial-induced changes in gene expression, contains independent activation domains. J Biol Chem 272, 19801-19807.

86. Liao, X.andButow, R. A. (1993) RTG1 and RTG2: two yeast genes required for a novel path of communication from mitochondria to the nucleus. Cell 72, 61-71.

87. Haynes, C. M.Petrova, K.Benedetti, C.Yang, Y.andRon, D. (2007) ClpP mediates activation of a mitochondrial unfolded protein response in C. elegans. Dev Cell 13, 467-480.

88. Horibe, T.andHoogenraad, N. J. (2007) The chop gene contains an element for the positive regulation of the mitochondrial unfolded protein response. PLoS ONE 2, e835.

89. Zhao, Q.Wang, J.Levichkin, I. V.Stasinopoulos, S.Ryan, M. T.andHoogenraad, N. J. (2002) A mitochondrial specific stress response in mammalian cells. Embo J21, 4411-4419. 
90. Martinus, R. D.Garth, G. P.Webster, T. L.Cartwright, P.Naylor, D. J.Hoj, P. B.andHoogenraad, N. J. (1996) Selective induction of mitochondrial chaperones in response to loss of the mitochondrial genome. Eur J Biochem 240, 98-103.

91. Aldridge, J. E.Horibe, T.andHoogenraad, N. J. (2007) Discovery of genes activated by the mitochondrial unfolded protein response (mtUPR) and cognate promoter elements. PLoS ONE 2, e874.

92. Chan, D. C. (2006) Mitochondria: dynamic organelles in disease, aging, and development. Cell 125, 1241-1252.

93. Gould, S. J.andValle, D. (2000) Peroxisome biogenesis disorders: genetics and cell biology. Trends Genet 16, 340-345.

94. Zeevaert, R.Foulquier, F.Jaeken, J.andMatthijs, G. (2008) Deficiencies in subunits of the Conserved Oligomeric Golgi (COG) complex define a novel group of Congenital Disorders of Glycosylation. Mol Genet Metab 93, 15-21.

\section{FIGURE LEGENDS}

Figure 1. Organelle autoregulation. When the functional capacity of a organelle becomes insufficient compared to cellular demand, a regulatory signal is transmitted to the nucleus, where transcription of relevant genes involved in function of the organelle is activated, resulting in augmentation of the functional capacity. 
Figure 2. ER stress response. When ER functions such as folding and

ERAD become insufficient in mammalian cells, the program of

transcriptional induction is activated through three response pathways,

leading to enhancement of the capacity of ER function or the apoptotic

removal of the compromised cell.

Figure 3. Peroxisome proliferation and mitochondrial retrograde signaling in yeast. Excessive amounts of fatty acids induce peroxisome proliferation to increase the capacity of processing fatty acids by $\beta$-oxidation, and also activate mitochondrial retrograde signaling to enhance the capacity of the glyoxylate cycle. Mitochondrial retrograde signaling is also activated by reduced levels of cytosolic ATP, to upregulate the capacity of the TCA cycle.

Figure 4. Mitochondrial unfolded protein response in C. elegans. Insufficiency of folding or degradation capacity in the mitochondria 
activates the mitochondrial unfolded protein response to enhance the capacity of the organelle.

(3,653 words, excluding references) 


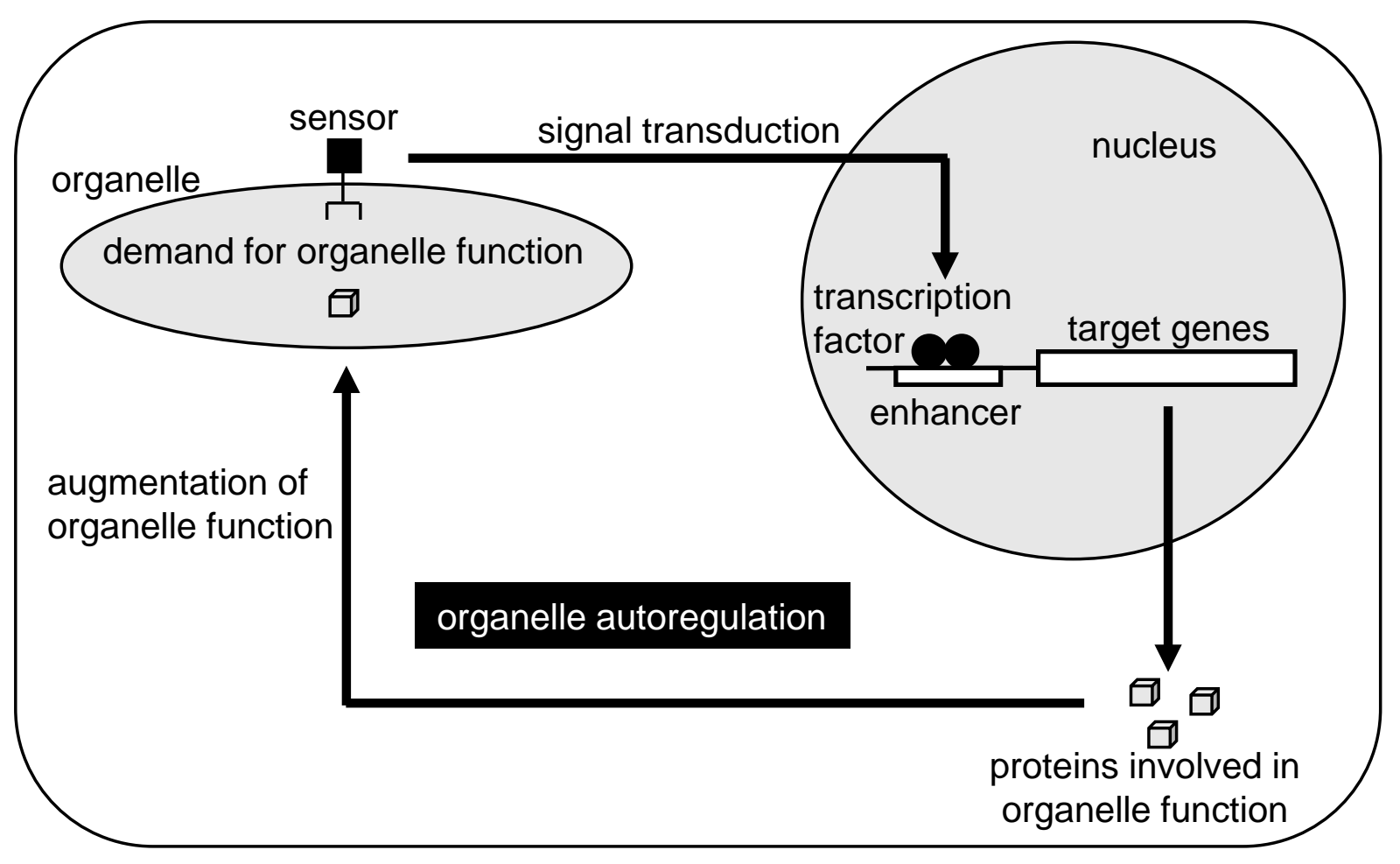




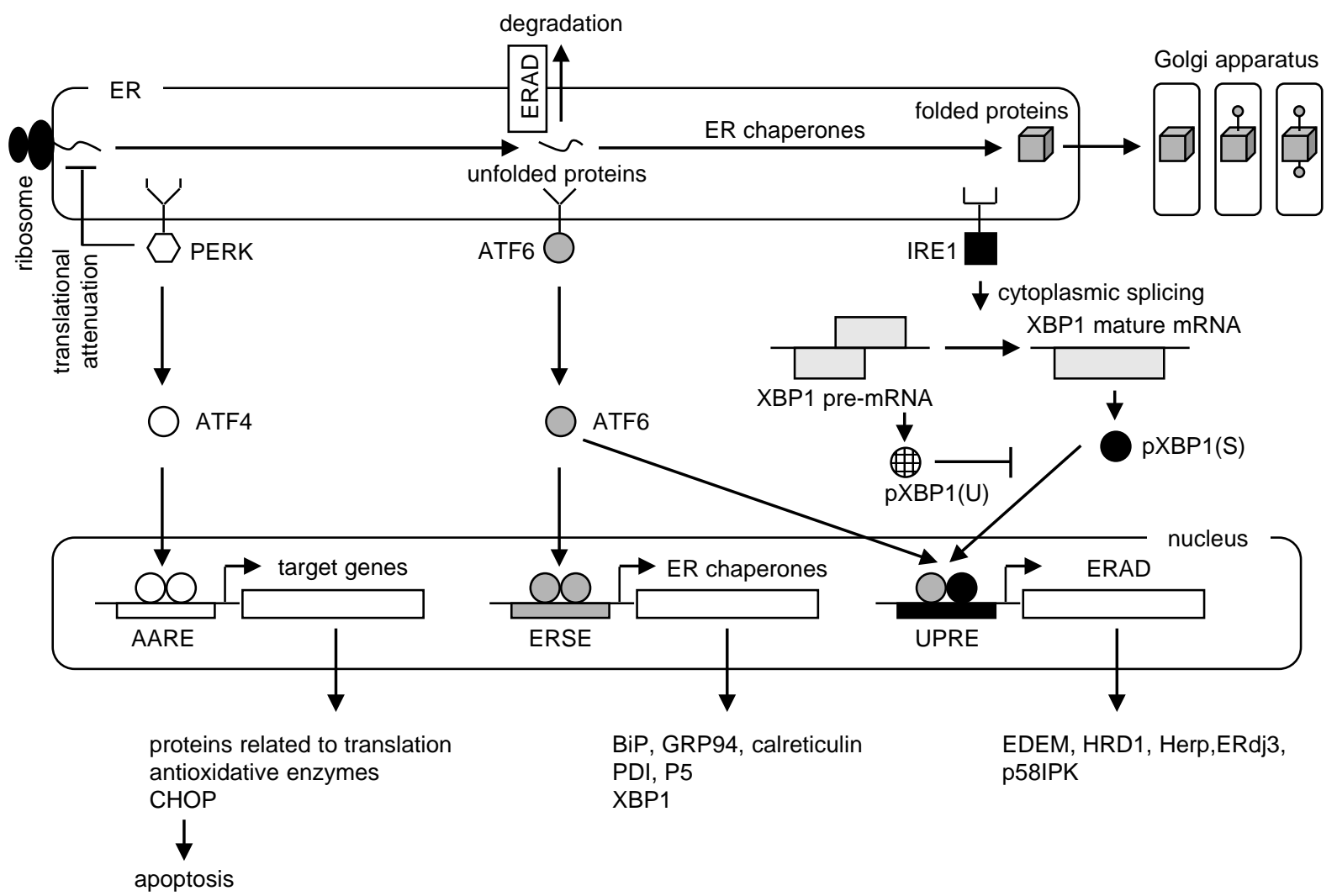




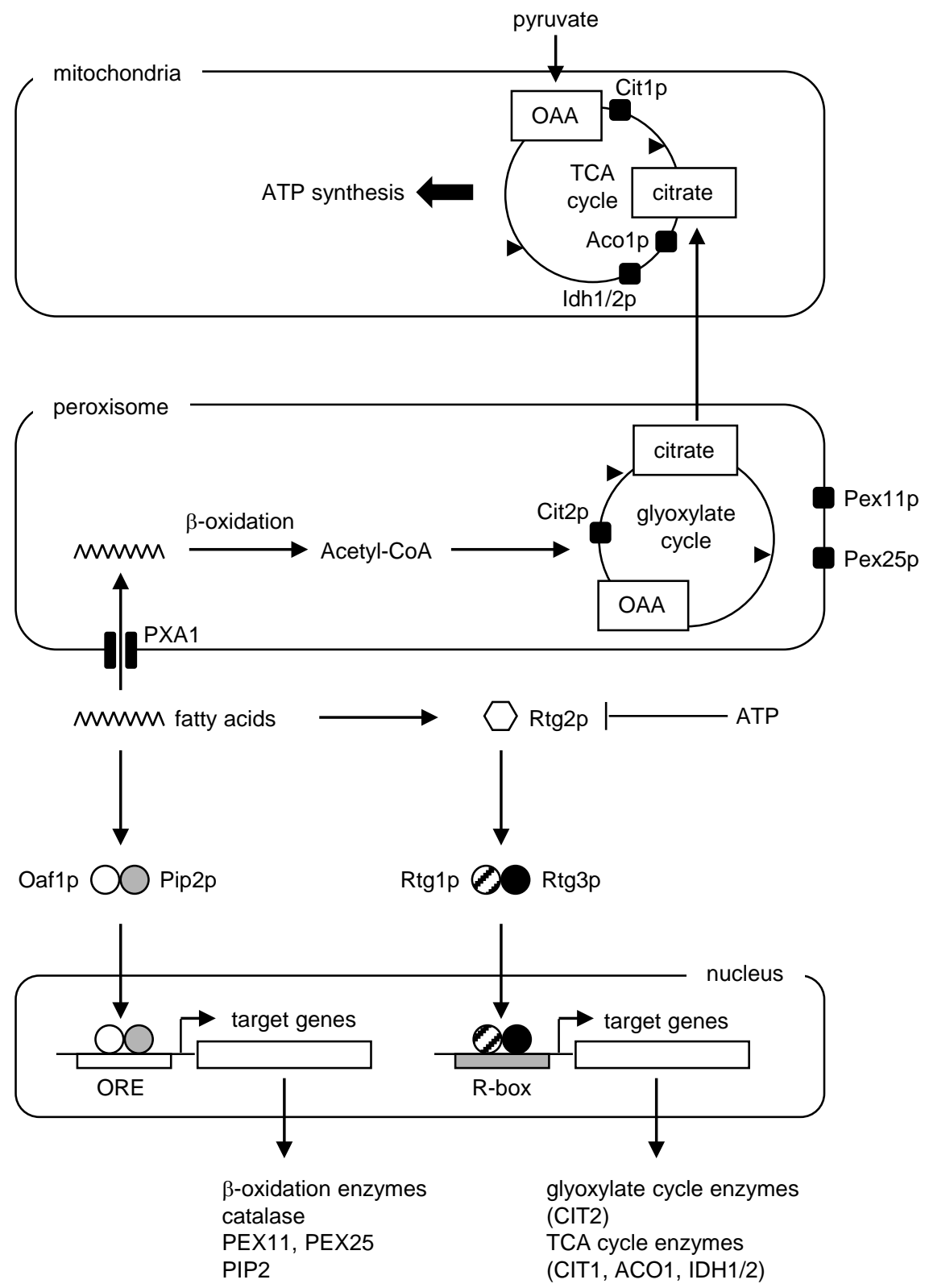




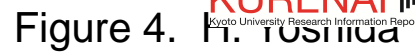

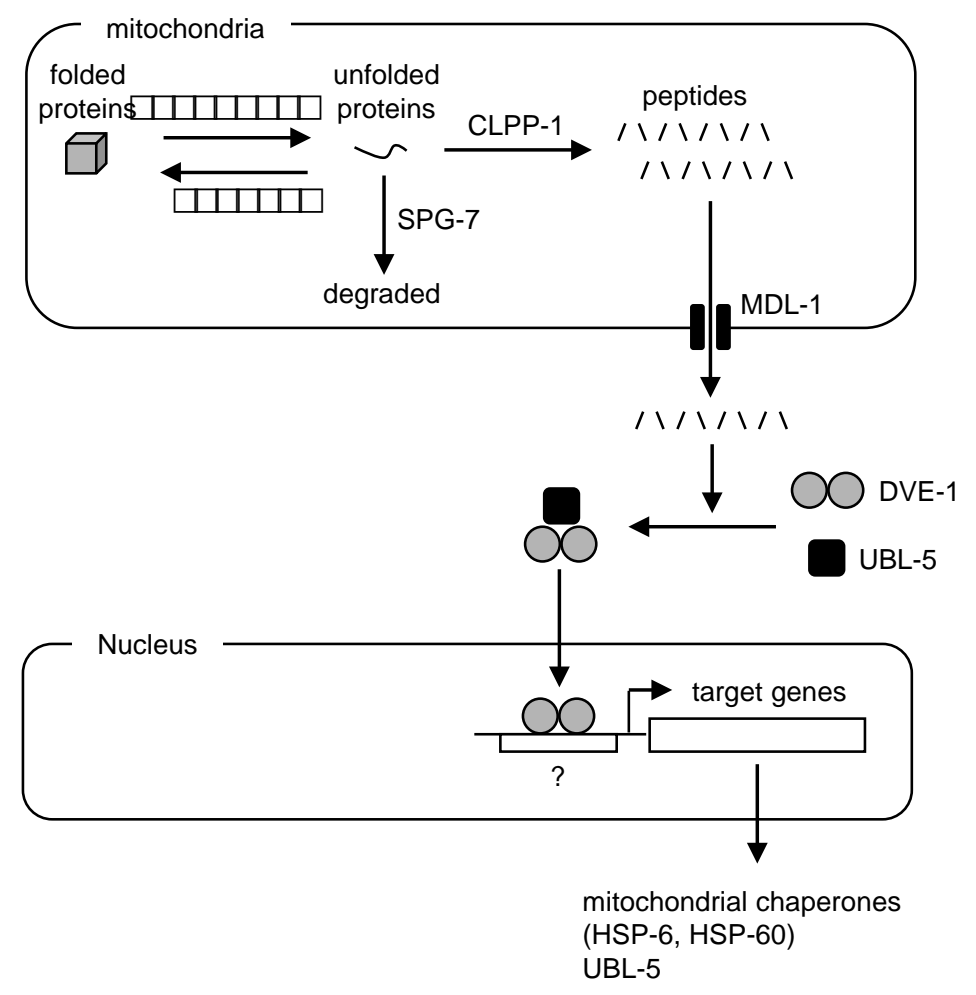

